\title{
QUESTÕES TEÓRICAS PARA UMA ETNOGRAFIA DO TOORO NAGASHI DE REGISTRO - SP
}

\author{
Josué Soares Flores*
}

\begin{abstract}
Resumo: Este artigo é parte de uma pesquisa sobre a celebração religiosa e as festas que cercam a soltura de tooro nagashi (lanternas flutuantes) no municipio de Registro, São Paulo. A influência da cultura japonesa trazida pelos imigrantes no início do século XX e as relações próprias estabelecidas dessa cultura com os costumes locais brasileiros desenvolveram traços importantes de uma genuína festa nipo-brasileira em culto à memória dos ancestrais, tanto das gerações fundantes da colônia quanto dos que faleceram na contemporaneidade. A construção do imaginário de uma sociedade dos mortos, convidada a festejar nesses dias, apaziguada por orações direcionadas a pessoas especificas e dispersadas pelos tooros iluminados com os nomes delas de volta ao "mundo dos mortos", estabelece uma realidade vista a partir de várias dimensões ou existências, a dos vivos e a dos que passaram pela morte. 0 Tooro Nagashi é, portanto, o reencontro espiritual dos vivos com os mortos, da memória com o presente, da história com o instante. Neste artigo, apontamos algumas questões epistêmicas, metodológicas e conceituais que são fundamentais para a discussão do fenômeno.
\end{abstract}

Palavras-chave: Tooro Nagashi. Imigração japonesa. Mortos. Ancestralidade. Memória.

\section{INTRODUÇÃO}

[...] toda pesquisa etnográfica tem seu principio nas "confissões" escritas ou inconfessadas. Lévi-Strauss (2008, p. 277).

Natural do estado do Rio Grande do Sul, de uma colônia de italianos, desde que fui transferido para o município de Registro, no Vale do Ribeira, em São Paulo, para assumir uma comunidade anglicana, segmento religioso do qual exerço o sacerdócio, tenho me empenhado em conhecer melhor a manifestação cultural e popular que ocorre todos os anos nos dias 1 e 2 de novembro, chamada Tooro Nagashi (lanternas flutuantes). Registro tornou-se, no início do século passado, importante colônia de imigrantes japoneses. Com eles, muitas tradições cultu-

\footnotetext{
* Doutor em Teologia pela Pontifícia Universidade Católica do Paraná (PUC-PR). Mestre em Antropologia pela Universidade Federal do Paraná (UFPR), em Teologia pela Pontificia Universidade Católica do Rio Grande do Sul (PUC-RS). Atualmente dedica-se ao sacerdócio na Igreja Episcopal Anglicana do Brasil no município de Registro/SP.
} 
rais japonesas passaram a ser reproduzidas onde antes era território caiçara, quilombola e indigena. Atualmente, o Tooro Nagashi é a manifestação que congrega a maior diversidade religiosa possível na região, e transcendeu os limites da tradição japonesa para uma releitura própria, local, original, baseada em muitas crenças e pela adesão popular de descendentes e não descendentes nipônicos. 0 Tooro Nagashi, em sua $65^{a}$ edição, em cerimônia pública, teve seu pedido de tombamento como patrimônio cultural imaterial junto aos representantes do Instituto do Patrimônio Histórico e Artístico Nacional (Iphan). Não obstante, iniciou de forma despretensiosa e em atenção - por parte do monge Emyo Ishimoto - ao desejo da família do viajante japonês afogado no rio Ribeira de Iguape, conforme lemos abaixo:

[...] Há mais de 60 anos, um viajante japonês hospedou-se numa pensão de Sete Barras e, numa manhã, desceu ao rio para lavar o rosto, caiu e se afogou. A familia dele no Japão pediu para Oboossan (monge) de Nichirenshu (uma das doutrinas do budismo) que um dia rezasse no Brasil pela alma do filho falecido. Em 1954, o casal Emyo e Myoho Ishimoto, recém-casados no Japão, veio para São Paulo quando a noiva tinha apenas 18 anos.

O senhor Emyo Ishimoto, Oboossan de Nichirenshu, procurou o senhor Bunzo Kassuga, único adepto da doutrina em Registro e realizou o $1^{\circ}$ Tooro Nagashi em 1955. Na primeira celebração, foram utilizados apenas 7 tooros (os barquinhos iluminados com vela soltos no Rio Ribeira).

0 sacerdote Emei [sic] Ishimoto e Bunzo Kasuga conseguiram a doação de um terreno da Prefeitura de Registro para construir o monumento em homenagem às vítimas de afogamento. 0 monumento foi erguido na Rua Miguel Aby-Azar, às margens do Rio Ribeira de lguape, onde é realizada anualmente a cerimônia religiosa do Tooro Nagashi (SHIMIZU, 2016, p. 127.).

As cerimônias do Tooro Nagashi iniciam no dia $1^{\circ}$ de novembro (Festa de Todos os Santos no calendário cristão) em ato inter-religioso no Cemitério da Saudade. A cada ano uma religião dirige a liturgia própria de seu costume e rito para a ocasião, que tem como objetivo agradecer a vida dos entes falecidos e rezar por suas almas. Essa cerimônia acontece em frente à Capela dos Nomes Esquecidos, que foi edificada pelo Bunkyo ${ }^{1}$ na década de 1990 com o objetivo de abrigar tabuletas de madeira com os nomes de pessoas que tem seus túmulos abandonados por diversas razões². Após essa cerimônia, ocorrem atividades culturais, beneficentes e gastronômicas em espaço apropriado na Praça Beira Rio.

1 - Trata-se de uma associação cultural da comunidade de descendentes de japoneses que conta com reconhecimento consular do Japão.

2 - Quando as pessoas não possuem parentes na região (especialmente aqueles que a familia tenha retornado ao Japão) e seus túmulos ficam visivelmente negligenciados, elas têm seus nomes restaurados em pequenas tabuletas, escritos em japonês ou em português, e pendurados nas paredes dessa capela. Diariamente, os(as) frequentadores(as) desse cemitério rezam pelos nomes das pessoas ali presentes. 
No dia seguinte, dia 2 de novembro (Dia de Todas as Almas no calendário cristão), ocorre, logo pela manhã, um rito de oração pelas almas dos acidentados na BR-116, em um cruzeiro às margens da rodovia, próximo a uma ponte que atravessa o rio Ribeira de Iguape. Essa cerimônia já é realizada há mais de 50 anos no mesmo local pelos adeptos da Seicho-no-iê. Diante do cruzeiro, são dispostas as oferendas e constituído o altar (onde também há outras oferendas). Ali, naquele altar, o preletor procede à leitura da Sutra sagrada chuva de néctar, finalizando com a oferenda de incenso e vela, por todos os presentes, em local apropriado. A festa segue com suas atividades na Praça Beira Rio até a celebração principal, que ocorre ao entardecer do mesmo dia.

Ao pôr do sol, inicia-se o lançamento das lanternas (tooros) ao rio. Em um lado da margem ficam algumas dezenas de voluntários(as) que irão descarregar os milhares de lanternas dos caminhões. Essas lanternas serão dispostas em longas fileiras aguardando o momento exato para serem colocadas no rio. Ao mesmo tempo, madre Myoho (sacerdotisa do budismo nicherenshu) irá, em uma balsa, juntamente com tocadores de taikô, navegar pelas águas do rio Ribeira de Iguape, a fim de purificar as águas. Imediatamente após a purificação das águas, ocorre, na margem principal (onde está o monumento dedicado às almas dos afogados no rio), uma concentração de centenas de pessoas, entre elas, líderes de outras religiões, figuras políticas, representantes de instituições e jornalistas. Junto ao monumento, são dispostos oferendas e um altar - ao estilo budista - onde será conduzido o rito de oração pelas almas dos afogados no rio Ribeira de lguape e todas as almas. 0 rito é finalizado com oferendas dos participantes em incenso em local apropriado. Ao final dessas orações, os tooros são soltos na outra margem do rio, tendo já a lua tomado seu lugar. 0 rio é tomado por luz e cores, uma profusão de beleza que atrai os olhares dos participantes ao deslizar lento e bucólico dos milhares de lanternas ao longo do grande leito do rio.

Após essa brevíssima descrição, gostaria de levantar algumas questões teóricas importantes a respeito daquilo que a teoria antropológica nos proporciona e suscita compreender sobre esse fenômeno da cultura popular típico dos descendentes nipônicos do Vale do Ribeira e seus impactos no imaginário e nas representações do sagrado.

\section{QUESTÕES EPISTEMOLÓGICAS}

Todo momento etnográfico, que é um momento de conhecimento ou de discernimento, denota uma relação entre a imersão e o movimento. Marilyn Strathern (2014, p. 350).

Se nos séculos passados a Antropologia se deu ao esforço colonialista - firmando, sobretudo, a hegemonia do caráter imperialista euro-americano -, nas últimas décadas, ela reviu 
seu método no que diz respeito às epistemologias empregadas. 0 lugar da fala etnográfica, a posição do observador na análise de conteúdo, o espaço de minorias no interior das sociedades estudadas, entre tantas outras 'viradas' epistêmicas, foram a contribuição madura de uma ciência nova.

Nas palavras de Dumont (1993, p. 16), "[...] existem duas maneiras de considerar um conhecimento qualquer, uma maneira superficial que deixa fora de questão o sujeito conhecedor, e uma maneira profunda que o inclui". A Antropologia se lança a um conhecimento profundo sobre o "outro", à busca da compreensão deles a partir de sua própria fala, superando as dicotomias civilizado/selvagem, como o próprio Dumont (1993, p. 18) afirma: "[...] o nosso sistema de valores determina toda a nossa paisagem mental". Abandonar nosso sistema de valores é uma outra forma de falar sobre objetividade. Essa é impossivel e desnecessária, o que se quer é ouvir a voz do outro, de sua própria narrativa, de sua própria interpretação e, para isso, a Antropologia será mais tradutora e menos interpretadora, ainda que traduzir já seja uma forma de interpretar. Assim, buscamos em Barth (2003) e sua teoria da etnicidade elementos de sua epistemologia que contribuam com nosso olhar.

\section{[...] Barth procura definir a cultura com base na força heuristica dos significados que os nativos dão às suas interações. [...] Um determinado evento pode ser vivido e interpretado a partir de diferentes modelos, de acordo com o contexto cultural do participante (LASK, 2000, p. 13).}

Apesar de, particularmente, ter dificuldades com a palavra definir, pois compreendo que esse conceito é pretensioso e arrogante, na citação acima, o exercício de compreensão do outro passa pelo próprio significado que o sujeito da ação dá para tal, e essas ações, nas bases teóricas da hermenêutica, podem e devem ser interpretadas (recebidas) de formas variadas por cada participante da ação. Há uma profusão de intersubjetividades, uma cascata fenomenológica de individualidades se manifestando na epifania da ação. É correto afirmar que cada ação é dotada de um sentido ou significado fundante, original, da gênese do ato (se é que podemos falar nesses termos sem apelarmos a uma ortodoxia da ação), mas é salutar e imprescindivel que o observador perceba a miriade de outras interpretações em um mesmo contexto, que são determinadas pelas experiências vividas a partir de cada ator social, na posição que cada um ocupa. "Para identificar as representações culturais utilizadas por determinadas pessoas, devemos nos voltar para o conhecimento e para o discurso que essas pessoas empregam para interpretar e objetivar suas vidas" (BARTH, 1993, p. 346-347). Dada essa complexidade do tecido social, a qual configura o objeto da Antropologia, o etnógrafo cada vez mais se dedica (e de fato é o campo por excelência da Antropologia como ciência) aos múltiplos microuniversos ou microcosmos. Não é possivel ter uma fala apenas que defina o que é um povo, senão múltiplas visões, conforme interpretam seus diferentes atores, que são o povo. 
E uma maneira de o(a) pesquisador(a) de campo fazer isso é se comprometer com as relações sociais que as pessoas desejam estabelecer com ele(ela) - pois, se assim desejarem, o(a) pesquisador(a) de campo se torna parte dessas relações. Imaginar que isso pode ou deve ser realizado para coligir dados melhores é pensar de trás para a frente. As relações devem ser valorizadas em si mesmas; qualquer informação resultante é um produto residual e muitas vezes inicialmente desconhecido. É isso que imersão quer dizer (STRATHERN, 2014 , p. 354).

Se por muito tempo, ao longo da trajetória epistemológica da Antropologia, falava-se sobre uma observação objetiva, que significava, sobretudo, um distanciamento entre etnógrafo e objeto, agora fala-se em processo de imersão. 0 grande edifício metodológico que guiou gerações de antropólogos no campo ruiu com o desvelar do mito da objetividade. Se a objetividade do observador se dá pelo distanciamento epistêmico, e nisso está a eficácia da análise dos dados, o erro já se dá na gênese da metodologia, uma vez que não entendemos como possivel qualquer conhecimento que se furte da relação. A Antropologia, enquanto ciência, é tributária em todas as suas fases de pesquisa (da fala, dos dados, das informações) ao processo de imersão fundado na relação estabelecida entre o observador e o objeto observado. Não há demérito ao(à) pesquisador(a) nos resultados obtidos a partir da relação senão honestidade intelectual e reconhecimento moral de que o conhecimento produzido é fruto dessa relação e que não poderia ser diferente, "[...] é a análise do efeito relacional que, em sua opinião, torna uma análise antropológica, 'coisas' e 'pessoas' podem ser copresenças num campo de atores dotados de efeito" (STRATHERN, 2014, p. 362).

Compreender a relação, ou melhor, os efeitos da relação, possibilitou à epistemologia antropológica um salto ontológico saindo das fronteiras de definição do 'outro' (como se fosse um alguém homogêneo) para uma presença mais focada nas microrrelações estabelecidas no interior das sociedades.

Os etnógrafos se colocam a tarefa de não só compreender o efeito de certas práticas e artefatos na vida das pessoas, mas também recriar alguns desses efeitos no contexto da escrita sobre eles. É claro que a análise (a "escrita") começa "em campo", assim como os anfitriões do(a) etnógrafo(a) continuam a exercer, muito depois, uma tração sobre a direção de suas energias. Ora, a divisão entre os dois campos cria dois tipos de relação (inter-relacionados). Um deles é a consciência aguda da tração exercida por trilhas divergentes de conhecimento, e o antropólogo pode considerar que uma dessas trajetórias pertence à observação e a outra, à análise; o outro é o efeito de envolver juntamente os dois campos, o que podemos chamar de momento etnográfico. 0 momento etnográfico é uma relação, assim como um signo linguístico pode ser pensado como uma relação (ao juntar significante e significado) (STRATHERN, 2014, p. 350, grifo do autor). 
Recriar o efeito dessas relações entre os atores sociais na análise (escrita), segundo Strathern (2014), é a tarefa e desafio do(a) etnógrafo(a). 0 momento etnográfico é o encontro entre dois campos de conhecimentos - o do observador e o do observado - estabelecido por meio da relação. A epistemologia antropológica, a fim de mediar o momento etnográfico (como encontro de ontologias distintas) recorrerá à alteridade observador/observado, resultante da imersão do etnógrafo, à produção de uma escrita que revele existencialmente e profundamente seu objeto

Dada a função religiosa que ocupo, meus estudos em antropologia quase sempre se voltam ao aspecto religioso e seus efeitos na vida social. Sabemos, sobretudo, que o campo da religião é tão somente um aspecto e nem o mais nem menos importante de uma sociedade, mas um aspecto fundamental para se compreender uma cultura. "A gestão da identidade, a formação da comunidade étnica, as leis e as políticas públicas, as medidas e os interesses dos regimes, bem como os processos globais, fundem-se e formam um complexo campo de politicas e processos culturais" (BARTH, 2003, p. 30). Essa complexidade apontada por Barth (2003) compromete o antropólogo a uma sólida e capilar formação em amplas e difusas áreas da atividade, pensamento e expressão humana, a fim de que a análise (escrita) esteja comprometida com a maior pluralidade e diversidade possivel. Este trabalho se debruçará fundamentalmente no desenvolvimento dos ritos religiosos a partir das noções e construções de identidade étnica, tendo como pano de fundo, ou contexto emergente, a preservação da memória e a ancestralidade nas narrativas da festa Tooro Nagashi.

\section{[...] a etnicidade é uma forma de organização social, o que implica que [...] "o foco principal da investigação seja a fronteira étnica que define o grupo e não o conteúdo cultural deste" (1969:15); a caracteristica distintiva dos grupos étnicos é [...] a auto-ascrição, bem como a ascrição por parte de terceiros (VERMEULEN; GOVERS, 2003, p. 9).}

Embora a cerimônia do Tooro Nagashi seja realizada pela Igreja Nicherenshu há 65 anos ininterruptos (inicialmente para adeptos dessa religião, posteriormente aberto à comunidade de descendentes nipônicos em geral e, então, aberto à comunidade ampla), o Tooro Nagashi encontrou espaço cultural para além de traços étnicos de sua prática fundante no Japão, difundindo-se amplamente entre não adeptos do budismo e não descendentes de japoneses. Ao mesmo tempo que a festa se difunde como uma prática ampla no universo regional, mantêm seus aspectos étnicos - de seu nascedouro cultural - protegidos como parte das tradições japonesas.

Contribuem para a assimilação dos costumes japoneses inúmeros eventos ao longo da história regional, entre eles, o mais destacado, o esforço da comunidade japonesa durante a Segunda Guerra Mundial, quando escolas japonesas foram fechadas, o idioma passou a ser proibido e agremiações sociais e religiosas de origem japonesa passaram a ser fiscalizadas. 0 
medo do estado policialesco sobre a vida comunitária contribui para uma mais rápida assimilação da língua, costumes e religião cristã, forjando, na comunidade étnica, aspectos que reverenciam suas origens, mas que, ao mesmo tempo, podem ser definidos como cultura nacional. Sobre isso, Barth (2003, p. 26) afirma: "O segundo grande processo pelo qual um nivel de descontinuidade é gerado tem lugar quando membros de um grupo convergem em comportamento e estilo devido a um código ou valor largamente partilhados e em relação ao qual tentam exceder-se". 0 processo de descontinuidade enfrentado pela comunidade japonesa no Brasil na primeira metade do século XX se deu pela coerção e opressão pela opressão do Estado, que percebeu nela um inimigo infiltrado, que devia ser combatido. Embora hoje o município seja majoritariamente habitado por descendentes de japoneses, a apatia com relação à esfera política é perceptível quando confrontamos as listas de vereadores e prefeitos de origem nipônica: são a minoria. Definitivamente o espaço público é o ambiente dos "nacionais", considerando que descendentes de japoneses ainda carregam o estigma de estrangeiros.

A relação entre etnicidade e cultura pode, na nossa opinião, ser vista como tripartida: a etnicidade refere-se à consciência da cultura (étnica), à utilização dessa cultura, sendo simultaneamente parte da mesma. Começando pela última questão, Barth definiu etnicidade como um elemento da organização social, mas defende que esta pode igualmente ser encarada como um elemento da cultura. As fronteiras podem ser vistas em termos interaccionais mas, de forma igualmente convincente, como "fronteiras da consciência", para utilizarmos a expressão de Cohen. As identidades étnicas são produto da classificação, da ascrição e da auto-ascrição, encontrando-se relacionadas com ideologias de ascendência, relacionando-se também o estudo da etnicidade com o da ideologia (Vermeulen 1984) e o dos sistemas cognitivos (Chapman et al. 1989). A etnicidade faz então parte da cultura e é também metacultural, no sentido em que constitui uma reflexão em torno da "nossa" cultura, bem como da "deles", e, em terceiro lugar, relaciona-se com o "uso subjectivo, simbólico ou emblemático", por parte de um "grupo de pessoas [...], de qualquer aspecto da cultura, de forma a diferenciarem-se de outros grupos" (De Vos 1975:16).

A concepção de etnicidade aqui apresentada, implica que a etnicidade enquanto elemento da organização social, requer interacção regulada e, enquanto elemento da cultura, implica consciência da diferença, em relação à qual alguns autores distinguem niveis "baixos" e "altos". No primeiro caso, as diferenças culturais tendem a ser marcadas e as relações interétnicas relativamente estáveis: as pessoas aceitam as diferenças como adquiridas, sem reflectir muito, não existindo uma ideologia étnica marcada e, muito menos, um movimento étnico. 0 oposto dá-se quando a interacção aumenta e as pessoas estão a perder, ou temem vir a perder, a sua singularidade cultural, "consciencializando-se", durante este processo, da sua cultura, podendo começar a "repará-la" e a exigir direitos culturais. A diferen- 
ça entre estas duas condições - extremos conceptuais do que é, de facto, um continuum - é indicada, entre outras, pelas noções de "solidariedade existencial" versus "solidariedade etnocêntrica" (Patterson 1977:43) e de "velha etnicidade" versus "nova etnicidade" ou "simbólica" (Gans 1979), relacionadas com a distinção de Roosens entre "cultura não reflectida" e "cultura reflectida" (1989) e a de Borneman entre "nacionalidade" e "nacionalismo", referidos por Verdery (VERMEULEN; GOVERS, 2003, p. 12-13).

Pontuamos como conceito fundamental para a discussão sobre os efeitos da festa do Tooro Nagashi as discussões sobre o conceito de etnicidade e identidade. Assim como as inúmeras expressões na cultura popular de ascendência africana, indígena ou europeia, já há no Brasil, especialmente em locais que abrigaram colônias, importantes relações estabelecidas entre a cultura japonesa e a dos povos provenientes da região, que, num processo ora de tensão ora de harmonia, trocam experiências culturais que darão feições novas para antigas práticas como nas palavras de Rubens Takeshi Shimizu (2019), membro da diretoria do Bunkyo de Registro: "aqui nós 'abrasileiramos' o Tooro Nagashi, no Japão é outra coisa". 0 que uma pessoa que participa da organização da festa representando o principal órgão de tradição e cultura japonesa da região quer dizer com isso? Quais são as implicações e os efeitos das relações estabelecidas entre os atores? Como esses efeitos são assimilados e vivenciados na experiência dos participantes no que diz respeito aos rituais de despedidas? Essas são algumas questões que, à luz de nossa observação, desejamos compreender.

\section{COMPREENDENDO EXPRESSÕES RELIGIOSAS}

Em outras palavras, apesar de a perspectiva religiosa não ser exatamente racional, ela também não é irracional.

Asad (2010, p. 275).

Memória e ancestralidade, longe de serem meros elementos retóricos dos cultos realizados durante os festejos, são elementos teológicos fundamentais para compreender a cosmologia e a escatologia dos participantes. Desprezar o argumento teológico, que é o suporte no qual gravitam todos os símbolos religiosos e não religiosos, seria um erro metodológico. Nas palavras de Leach (1975, p. 35, tradução nossa): "[...] o ritual é uma exposição simbólica que diz algo sobre os indivíduos que participan na ação". Por isso, debruçamo-nos sobre os aspectos intrínsecos dos ritos religiosos para compreender os indivíduos que realizam tais ações. Como a epígrafe registra, a perspectiva religiosa não tem a pretensão de ser racional - embora o termo aqui seja semanticamente cientificista -, mas também não é irracional. Toda ação religiosa tem um sentido e coerência própria que se explicam por meio de seus 
próprios mitos fundantes, de suas escrituras e objetos sagrados, e da observância estrita dos ritos presididos pela figura legitima para tal.

No nivel do cotidiano, nos ritos de caça e outros atos da vida normal do acampamento; em circunstâncias excepcionais, seja para a vida do indivíduo ou para do grupo. No nível do indivíduo, estão os rituais que acompanham seu nascimento, a puberdade das meninas, o matrimônio e a enfermidade. No nível do bando, encontram-se os rituais coletivos que acompanham a puberdade e a morte (os rituais elima para a puberdade e molimo para a morte). Quando a enfermidade se abate de maneira crônica sobre um bando, celebra-se "um pequeno ritual molimo" para solicitar à benevolência da selva e sua proteção. Assim pois, a religião é um ato cotidiano e ao mesmo tempo uma atividade que aparece em cada momento crítico ou do desenvolvimento do indivíduo e da reprodução do bando em seu conjunto, como uma unidade social orgânica (GODELIER, 1974, p. 349, grifo do autor).

Para Godelier (1974), os ritos religiosos se manifestam ao longo da vida dos individuos como ritos de transição ou como ritos de momentos críticos. De fato, concordamos com ele sobre essa sentença, mas discordamos do fato de que os ritos religiosos ocorram apenas nas transições ou em momentos críticos. A religião está marcadamente presente em todos os momentos, mesmo que na reprodução diária de ritos muito pessoais, particulares, individuais, mas que encontram respaldo em costumes e usos coletivos. A religião está impregnada em nossos costumes diários, seja nas situações mais simples ou mais complexas. Reduzir a presença do religioso ou do sagrado apenas às transições parece-nos um reducionismo da importância e do papel exercido por essa.

A crença religiosa sempre envolve "uma aceitação prévia da autoridade" que transforma a experiência: A existência da perplexidade, da dor e do paradoxo moral - do Problema do Significado - é uma das coisas que impulsionam os homens para a crença em deuses, demônios, espíritos, princípios totêmicos ou a eficácia espiritual do canibalismo [...], mas essa não é a base onde repousam tais crenças, e sim seu campo de aplicação mais importante (GEERTZ, 1989, apud ASAD, 2010, p. 273, grifo do autor).

A "autoridade" mencionada acima trata dos múltiplos elementos de autoridade que cada religião possui, a saber, um livro, um objeto, um lugar, uma pessoa sagrada etc. 0 fato de que tal autoridade transforma a experiência, no sentido de que dá um novo sentido a uma trajetória de vida, também deforma essa trajetória quando, sobre a experiência, exerce abusivamente seu poder de coação social. Para Asad (2010), a base na qual repousam as crenças é existencial. Se, por um lado, é a existência "da perplexidade, da dor e do paradoxo moral" o nascedouro do problema do significado, por outro lado, é ela também a base sobre a qual 
repousam todas as crenças religiosas, no sentido de que elas buscam dar uma resposta possivel ao problema (nauseante) da angústia pela falta de significado ao problema do mal e do sofrimento. Nesse sentido, a pergunta sobre a morte, o sofrimento humano e as tragédias vividas sucedidas pela morte, a efemeridade da vida e o boicote de uma vida sonhada e projetada para o futuro são questões fundamentais nos ritos funerários e, particularmente, no Tooro Nagashi, uma festa em celebração à memória dos finados, causando-nos estranhamento. Nossa tradição cristã-ibérica, que não dá brecha à celebração em memória dos mortos, reforça o luto como respeito à dignidade do ente falecido, trajando-se de sobriedade e dando um tom solene ao silêncio obsequioso do dia. Como os sentimentos e as experiências de dor e sofrimento podem ser rememorados em festa? E que sentido há em tais elementos ritualísticos do Tooro Nagashi para o enfrentamento das questões existenciais de fundo, que são a origem e o fim da manifestação cultural e religiosa?

\begin{abstract}
[...] a tão controvertida questão das relações entre magia e religião se esclarece. Pois se, num certo sentido, pode-se dizer que a religião consiste em uma humanização das leis naturais e a magia em uma naturalização das ações humanas - tratamento das ações humanas como se elas fossem uma parte integrante do determinismo físico - não se trata dos termos de uma alternativa ou das etapas de uma evolução. 0 antropomorfismo da natureza (em que consiste a religião) e o fisiomorfismo do homem (pelo qual definimos a magia) formam dois componentes sempre dados e cuja dosagem apenas varia. [...] cada uma delas implica a outra. Não existe religião sem magia, nem magia que não contenha pelo menos um grão de religião. A noção "de uma supernatureza existe para uma humanidade que atribui a si mesma poderes sobrenaturais e que, em troca, empresta à natureza os poderes da super-humanidade" (LÉVI-STRAUSS, 2008, p. 247).
\end{abstract}

Lévi-Strauss (2008) tem razão ao conectar religião e magia no limite de suas ausências de resposta. Como sacerdote, observo que mediante questões importantes e profundas feitas pelos fiéis, minhas respostas vão do superficial ao limite do dogma, da tradição, da experiência de fé (variando conforme o grau de conhecimento de cada um), mas muitas vezes não posso dizer aquilo que o fiel espera ouvir, não por falta de domínio, mas por não dispor de qualquer legitimidade e autoridade, pois estaria adentrando outros campos, o que partiria para uma heterodoxia perigosa, ou, como dizem: heresia. Não porque a heresia seja impensada, mas porque toda heresia extrapola as fronteiras do dogma, avança num terreno pantanoso para além do chão concreto dos fundamentos das doutrinas. Entretanto, esse é um caminho trilhado livremente pelos fiéis que, na busca de respostas, encontram limites e ausências que serão compensadas em outras tradições religiosas e na magia. "0 meu argumento é que não pode haver uma definição universal de religião, não apenas porque seus elementos constituintes e suas relações são historicamente específicos, mas porque esta 
definição é ela mesma o produto histórico de processos discursivos" (ASAD, 2010, p. 264). Concordamos com o autor sobre a impossibilidade de uma definição universal de religião. Há, sim, um diálogo fértil e subterrâneo sobre a diversidade religiosa, ou seja, pontos de contato nas raizes mais profundas das religiões, que as ligam a experiências semelhantes e ao mesmo tempo tão distintas, de modo orgânico ou não institucional. Se é possivel falarmos em um presente etnográfico, é possivel também falarmos em um presente da experiência religiosa. Cada tradição religiosa sofre influências e, por sua vez, também influencia as demais tradições religiosas. Assim, qualquer definição sobre religião é um produto histórico de uma narrativa especifica.

\section{MEMÓRIA E ANCESTRALIDADE}

A celebração do Tooro Nagashi tem como ápice o lançamento de lanternas no rio Ribeira de Iguape. Essas lanternas são pequenas armações de bambu envoltas por papel seda que flutuam sobre o rio. A cor do papel pode variar, entretanto nele está escrito, em língua japonesa ou portuguesa, o nome do(a) falecido(a) ou o sobrenome da familia a qual se presta culto. 0 ente pode ser adulto ou criança, pode ter morrido há pouco ou há muito tempo, pode ser familiar ou apenas um amigo. Durante o cerimonial, há um apelo forte ao orgulho em relação à imigração japonesa e um sentimento de gratidão pelo trabalho, esforço e vida dos vivos com relação aos antepassados.

\footnotetext{
[...] a fidelidade obstinada a um passado concebido como modelo intemporal mais que como uma etapa do devir não trai nenhuma carência moral ou intelectual; ela exprime um partido adotado consciente ou inconscientemente e cujo caráter é confirmado no mundo inteiro por essa justificação incansavelmente repetida de cada técnica, de cada regra e de cada costume, através de um único argumento: os antepassados nos ensinaram. Como para nós, em outros domínios e até uma época recente, a antigüidade e a continuidade são os fundamentos da legitimidade. Mas essa antigüidade é colocada no absoluto, pois que remonta à origem do mundo, e essa continuidade não admite orientação nem gradação (LÉVI-STRAUSS, 2008, p. 262).
}

Muito além de representar os dados historiográficos concernentes à imigração, os descendentes japoneses cultivam em suas tradições um elemento ontológico com o passado, uma etno-ontogenia, a origem civilizatória de um povo. Quando Lévi-Strauss (2008, p. 262) afirma "os antepassados nos ensinaram", reitera a importância da tradição recebida. Manter e reproduzir o modo de fazer e de ser constituem laços de afetividade e experiência direta com a memória e a ancestralidade. 
Graças ao ritual, o passado "disjunto" do mito articula-se de um lado com a periodicidade biológica e sazonal e de outro com o passado "conjunto" que liga ao longo das gerações os mortos e os vivos. Esse sistema sincro-diacrônico foi bem analisado por Sharp $(1943,71)$, que classifica os ritos das tribos australianas da península do Cabo lorque em três categorias. Os ritos de controle são positivos ou negativos, visam a aumentar ou restringir as espécies ou fenômenos totêmicos, tanto em benefício quanto em detrimento da coletividade, fixando a quantidade de espíritos ou de substância espiritual cuja liberação será permitida, nos centros totêmicos estabelecidos pelos ancestrais, em diversos pontos do território tribal. Os ritos históricos ou comemorativos recriam a atmosfera sagrada e benéfica dos tempos míticos - época do "sonho", dizem os australianos - a cujos protagonistas e grandes feitos refletem, como num espelho. Os ritos de luto correspondem a um processo inverso: ao invés de confiar aos homens vivos o encargo de personificar os antepassados distantes, esses ritos asseguram a reconversão, em antepassados, de homens que deixaram de ser vivos. Vê-se, então, que o sistema do ritual tem por função superar e integrar três oposições: a da diacronia e da sincronia, a dos caracteres periódico ou aperiódico que ambas podem apresentar e, enfim, no interior da diacronia, a do tempo reversivel e do tempo irreversivel, pois, se bem o presente e o passado sejam teoricamente diferentes, os ritos históricos transportam o passado no presente, e os ritos de luto, o presente no passado, não sendo equivalentes os dois processos; dos heróis míticos, pode-se verdadeiramente dizer que voltam, pois toda sua realidade reside em sua personificação, mas os humanos morrem de fato (LÉVI-STRAUSS, 2008, p. 262-263).

Figura 1 Esquema sobre os Ritos de Luto

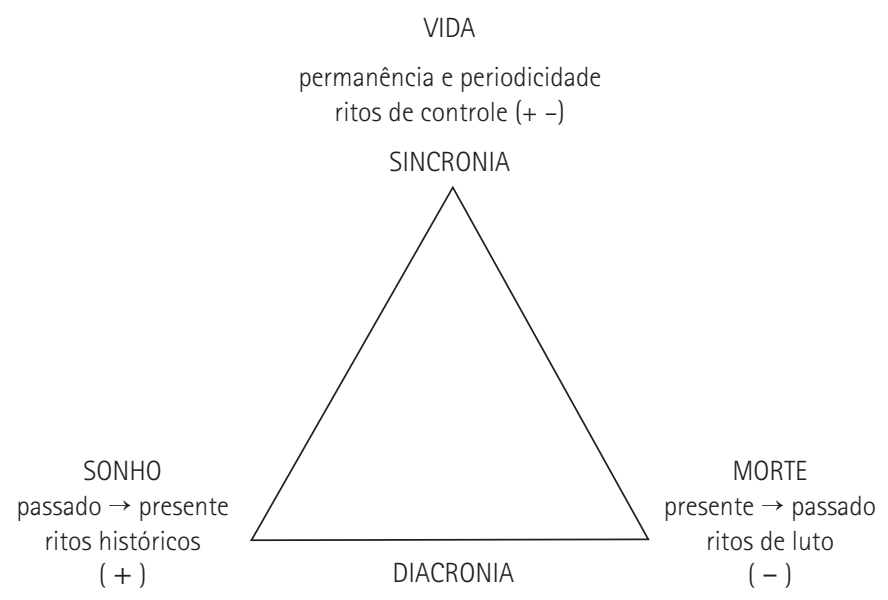

Fonte: Lévi-Strauss (2008, p. 263). 
Em muitos relatos, pessoas entrevistadas afirmam que a oferenda da lanterna lançada ao rio é como as velas e flores no túmulo do ente no cemitério. Contudo, em alguns desses relatos, há uma importante explicação escatológica que envolve a sincronia e a diacronia, sobre as quais Lévi-Strauss comenta acima. Todo o cerimonial budista é realizado às margens do rio e de frente para um monumento em homenagem aos afogados do rio Ribeira de Iguape. Esse ritual busca estabelecer uma atmosfera de harmonia entre o universo dos entes vivos e o não lugar dos entes mortos. Esse não lugar é o mesmo ambiente, material e físico, compartilhado pelos vivos e pelas almas dos entes falecidos. ${ }^{3}$ Por isso, diante do monumento dedicado às almas dos afogados, há uma diversidade de oferendas de toda espécie: doces, cervejas, flores, cartões, que visam a acolher a alma dos que ouvirem e forem atraídos pelos sons dos tambores (taikôs), sinos e pela vibração das orações. As narrativas também afirmam que a festa que ocorre em meio às cerimônias fúnebres são para melhor acolher essas almas que, em outra forma, partilharão do mesmo espaço. Acolher bem os espíritos é parte da gratidão aos antepassados.

Os ritos comemorativos e funerários postulam que entre o passado e o presente é possivel a passagem nos dois sentidos; eles não fornecem a prova disso. Pronunciam-se sobre a diacronia mas fazem-no ainda em termos de sincronia, pois somente o fato de celebrá-los equivale a mudar o passado em presente. Concebe-se, portanto, que certos grupos tenham procurado reconhecer, de uma forma tangivel, o ser diacrônico da diacronia no interior da própria sincronia (LÉVI-STRAUSS, 2008, p. 263).

A tensão escatológica da celebração do Tooro Nagashi, como dissemos anteriormente, começa pelo culto aos ancestrais desvelado nas narrativas da imigração japonesa, entretanto, a tensão se reforça à medida que o mito explica as razões do Tooro Nagashi. 0 tooro, marcado com os nomes dos falecidos e iluminado por vela, tem a função de guiar a alma do ente falecido até o destino final da lanterna. Essa lanterna deve descer rio abaixo até chegar ao mar e, nele, buscar o caminho da ilha na qual as almas dos antepassados deverá habitar e para a qual todos iremos. Essa narrativa nos lembra o mito do Baloma, descrito por Malinowski. Assim, temos uma tensão entre sincronia e diacronia - o tempo cronológico dos vivos e o não tempo dos mortos - cortada transversalmente por uma realidade binária, ou seja, uma que se observa em contiguidade de um passado tangivel historicamente, e outra

\footnotetext{
3 - Para Leach (1975, p. 27), "las sociedades reales existen en una dimensión de tiempo y de espacio. [...] Cualquier sociedad real es un proceso en el tiempo. [...] existen cambios que reflejan alteraciones de la estructura formal". Concordamos com o autor sobre o fato de que as sociedades reais existem na dimensão de tempo e espaço, mas que a realidade é composta por um tecido de não realidade, de uma tecitura metafísica que dá sentido às ações dos indivíduos na realidade.
} 
que se projeta sempre para o futuro escatológico. A primeira relacionada aos vivos e a segunda, aos mortos.

\begin{abstract}
Entretanto, seria um erro crer que a selva é concebida pelos mbuti como uma realidade completamente distinta deles mesmos. Para eles, a selva é tudo quanto existe; as árvores, as plantas, os animais, o sol, a lua e os próprios mbuti. Quando um mbuti morre, sua respiração o abandona e se confunde com o vento, que é a respiração da selva. Os homens são pois, uma parte desta totalidade que existe além do mais uma pessoa onipresente e onipotente (GODELIER, 1974, p. 349, grifo do autor).
\end{abstract}

Godelier (1974) faz uma ontologia mbuti no espaço, o que também, a meu ver, é possível fazer no tempo, ou seja, uma relação ontológica dos indivíduos no tempo. 0 passado e 0 futuro são porosos, respirantes e permeadores das tecituras do presente. A realidade é permeável às influências de um tempo sincrônico-diacrônico que torna os vivos uma clivagem entre a ancestralidade e o futuro. 0 culto aos ancestrais, além de resgatar a memória - por meio da reflexão elaborada nas narrativas -, transporta o indivíduo à condição de sua futuridade, o de habitar o não lugar em um tempo que se enverga entre a memória (história) e a ancestralidade futura (escatologia), enquanto invoca a alma dos falecidos como no Tooro Nagashi.

\title{
CONCLUSÃO
}

Há muito a ser descortinado nas incontáveis páginas de etnografia que já temos nos dedicado a desvelar. 0 que apresentamos aqui foi uma pequena contribuição sobre questões onto-antropológicas acerca da ancestralidade e memória, religião e magia, etnicidade e assimilação dos descendentes de imigrantes japoneses de Registro. As cerimônias fúnebres, presentes na celebração ou festa do Tooro Nagashi, representam uma forma importante de se pensar o tempo, na dimensão da história e do eskathós (últimas coisas), e demonstram como essa narrativa religiosa constrói e reproduz essa visão de mundo. Por isso é fundamental abordar pontos importantes da epistemologia, próprios para compreender tais fenômenos, sem incorrer em possíveis equívocos metodológicos, como o desprezo daquilo que nos é muito caro, a saber, fenômenos étnico-religiosos com uma teologia muito particular, que transmuta um dia de luto para um dia de festa, de uma história que é concebida sob um continuum de seus personagens, atores e protagonistas. 


\title{
Theoretical questions for an ethnography of the Tooro Nagashi de Registro - SP
}

\begin{abstract}
The following article is part of a research on the religious celebration and the parties surrounding the release of tooro nagashi in the municipality of Registro, São Paulo. The influence of Japanese culture brought by immigrants in the early 20th century and the specific relations established by this culture with local Brazilian customs developed important features of a genuine Japanese-Brazilian festival in worship of the ancestors' memory, both the founding generations of the colony and the contemporary deceased. The construction of the imaginary of a society of the dead, invited to celebrate these days, appeased by prayers addressing specific people and dispersed by the illuminated tooros with their names back to the "world of the dead" establishes a reality seen from various dimensions or existences, that of the living and that of those who have gone through death. Tooro Nagashi is, therefore, the spiritual reunion of the living with the dead, the memory with the present, the history with the instant. In this article, we point out some epistemic, methodological and conceptual issues that are fundamental to the discussion of the phenomenon.
\end{abstract}

Keywords: Tooro Nagashi. Japanese imigration. Dead. Ancestrality. Memory.

\section{REFERÊNCIAS}

$A S A D, T$. A construção da religião como uma categoria antropológica. Cadernos de Campo, São Paulo, v. 19, n. 19, p. 263-284, 2010.

BARTH, F. Balines worlds. Chicago: The University of Chicago Press, 1993.

BARTH, F. Temáticas permanentes e emergentes na análise da etnicidade. In: VERMEULEN, H.; GOVERS, C. (org.). Antropologia da etnicidade: para além de "Ethnic groups and boundaries". Tradução Rogério Puga. Lisboa: Fim de Século, 2003. p. 19-44.

DUMONT, L. O individualismo: uma perspectiva antropológica da ideologia moderna. Tradução Álvaro Cabral. Rio de Janeiro: Rocco, 1993.

GODELIER, M. Economia, fetichismo y religion en las sociedades primitivas. Madri: Siglo Veintiuno Editores, 1974.

LASK, T. Apresentação. In: BARTH, F. O guru, o iniciador e outras variações antropológicas. Tradução John Cunha Comerford. Rio de Janeiro: Contra Capa Livraria, 2000. (Coleção Typographos).

LEACH, E. R. Sistemas politicos de la Alta Birmania: estudio sobre la estructura social Kachin. Barcelona: Editorial Anagrama, 1975.

LÉVI-STRAUSS, C. O pensamento se/vagem. Tradução Tânia Pellegrini. 8. ed. São Paulo: Papirus, 2008. 
SHIMIZU, R. T. (org.). Álbum comemorativo do centenário da colonização japonesa no Vale do Ribeira: Iguape, Registro e Sete Barras (1913-2013). Registro: Fundação Kunito Miyasaka/ Associação Cultural Nipo-Brasileira de Registro, 2016.

SHIMIZU, R. T. Entrevista. [out. 2019]. Entrevistador: Josué Soares Flores. Registro, 2019. 1 arquivo .mp3 (60min.).

STRATHERN, M. O efeito etnográfico e outros ensaios. Tradução Iracema Dulley, Jamille Pinheiro e Luísa Valentini. São Paulo: CosacNaify, 2014.

TAMBIAH, S. J. Culture, thought, and social action. Cambridge: Harvard University Press, 1985.

VERMEULEN, H.; GOVERS, C. Introdução. In: VERMEULEN, H.; GOVERS, C. (org.). Antropologia da etnicidade: para além de "Ethnic groups and boundaries". Tradução Rogério Puga. Lisboa: Fim de Século, 2003. p. 9-18. 